\title{
CADEIA PRODUTIVA DO SURURU levantamento de demandas relacionadas a qualidade de vida dos trabalhadores
}

\author{
Steffane Luiza Costa Neves \\ Juliana Donato de Almeida Cantalice
}

\begin{abstract}
Resumo: A cadeia produtiva do sururu consiste em fases que resultam em um longo e árduo processo no qual os trabalhadores submetem-se constantemente a condições precárias de trabalho. Sob esse prisma, o presente artigo busca descrever o ambiente, os processos, métodos e as condições de trabalho que envolvem o ofício e identificar os problemas ergonômicos que podem comprometer a qualidade de vida dos trabalhadores. Para tanto, a pesquisa foi desenvolvida através da pesquisa de campo juntamente à embasamentos teóricos, utilizando-se de uma metodologia baseada na Análise Ergonômica do Trabalho (AET) proposta por Wisner (1987) e Vidal (2008), a partir da conjugação de métodos observacionais e interacionais. Os métodos empregados sob esse contexto, possibilitará a discussão e inserção da ergonomia e do design, com o objetivo de estabelecer uma breve reflexão sobre a relação desses campos e o processo de trabalho artesanal.
\end{abstract}

Palavras-chave: design, ergonomia, produções artesanais, cadeia produtiva do sururu

\section{INTRODUÇÃ̃O}

Típico da culinária do Nordeste, o sururu é um molusco que compõe a identidade e o contexto histórico de Alagoas, sendo registrado oficialmente em 2014 como Patrimônio Imaterial Cultural do estado. Nesse contexto, a pesca é uma das principais fontes de subsistência de populações desassistidas que vivem às margens lacustres, sendo um ofício que envolve trabalhadores adultos, jovens e até crianças.

Sua cadeia produtiva é composta por fases e subfases que resultam em um longo e árduo processo no qual os envolvidos submetem-se constantemente a condições precárias de trabalho. Aliada à ausência de produtos apropriados, as inadequações ergonômicas associadas ao processo englobam problemas relacionados à má postura, sobrecarga física, movimentos repetitivos, lesões, inalação de fumaça e apneias contínuas, assim como a exposição e o contato com o ambiente insalubre, tornam os trabalhadores propensos a desenvolver doenças ocupacionais que podem influenciar na qualidade de vida dos mesmos.

Nessa perspectiva, têm-se o design como um meio para estabelecer uma melhor relação entre o produto, o ambiente e a sociedade. Pazmino (2007) coloca que o papel do design para a sociedade consiste no desenvolvimento de produtos que atendam às necessidades de cidadãos menos favorecidos, social, cultural e economicamente. No entanto, para que seja possível atender às necessidades reais dos usuários, primeiramente é necessário ser sensível aos aspectos técnicos, culturais, sociais, econômicos e geográficos que envolvem a situação.

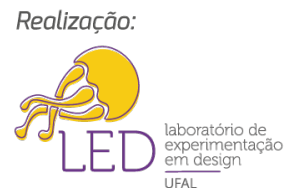


Nesse âmbito, sendo um campo de estudo do design, a ergonomia, conforme a Associação Brasileira de Ergonomia - ABERGO (2000), é um campo que objetiva melhorar de forma integrada a segurança, conforto, bem-estar e a eficácia das atividades humanas. Niemeyer (2008), corrobora que devemos discutir o papel do designer em processos de intervenção através da análise ergonômica, de forma que este deverá conhecer as tendências e os parâmetros que as guiam.

Partindo de um pressuposto da necessidade de um produto adequado para a realização do ofício em questão, o presente estudo tem foco no levantamento dos problemas encontrados na cadeia produtiva do sururu, com foco na análise ergonômica, objetivando posteriormente promover melhorias ao processo de produção por meio do design.

O estudo aqui apresentado foi desenvolvido a partir da conjugação de pesquisas bibliográficas, através da interpretação e análise de livros, publicações científicas, documentos, reportagens, documentários, etc., e da pesquisa de campo, onde os fatos e fenômenos foram observados e analisados, objetivando compreender e explicar o problema pesquisado.

Para o levantamento e análise de dados apresentados, utilizou-se de uma abordagem metodológica baseada na Análise Ergonômica do Trabalho (AET), proposta por Wisner (1987) e Vidal (2008). Os autores caracterizam a AET como um conjunto estruturado de análises intercomplementares dos determinantes da atividade das pessoas em uma organização. Sendo a análise ergonômica o foco do presente estudo, para conhecer de forma aprofundada o universo dos trabalhadores pesquisados, foram aplicados métodos propostos pela metodologia em pauta: interacionais (ações conversacionais, verbalizações espontâneas e provocadas) e observacionais (observação da atividade, registros em vídeos e fotografias).

Com os métodos aplicados sob esse contexto, foi possível realizar um diagnóstico ergonômico preliminar, bem como estabelecer uma discussão sobre a relação do design, ergonomia e as produções manuais (com foco na cadeia produtiva do sururu), sendo sensível aos aspectos ambientais, culturais, sociais, econômicos e geográficos que envolvem a situação.

Para melhor entender a correlação entre o design, a ergonomia e as práticas artesanais, convém deter-se sobre cada um desses conceitos e como estes relacionamse. Desse modo, a seguir serão explanados os campos atuantes do estudo, transitando pelos conceitos do design, ergonomia, a abordagem metodológica da AET e suas bases da antropotecnologia, objetivando estabelecer uma breve reflexão sobre a influência desses campos para o processo de trabalho artesanal, com foco na produção do sururu.

\section{DESIGN, ERGONOMIA E PRÁTICAS ARTESANAIS}

Pode-se afirmar que o design é um campo que possui uma relação direta com a sociedade, na qual sua principal função consiste no desenvolvimento de soluções adequadas à determinadas situações. Dentro do escopo design-sociedade, é importante destacar o foco em demandas de populações menos favorecidas social, cultural e economicamente buscando atender suas verdadeiras necessidades, principalmente onde não há a inserção do design.

Estes fatores, por sua vez, exigem uma interdisciplinaridade em todos os campos de atuação do design. Para isto, a ergonomia deve ser parte integrante durante o processo de identificação de demandas, uma vez que a mesma se qualifica como uma abordagem sistêmica de todos os aspectos da atividade humana, conforme a ABERGO (2000). Ainda segundo a Associação, é preciso ter uma visão holística de todo o campo de ação, tanto 
em seus aspectos físicos e cognitivos, como sociais, organizacionais, ambientais, etc. A ergonomia vista como uma das áreas de estudo do design, pôde ser aplicada à prática produtiva de muitas empresas e ambientes de trabalho ao longo dos anos, entretanto, práticas mais antigas como as produções artesanais não são proporcionalmente contempladas.

Imergindo no universo das práticas artesanais, dentre as diversas produções manuais presentes no Brasil, encontra-se a pesca artesanal. Essa tipologia representa uma importante modalidade de trabalho: dados oficiais de 2006 da Secretaria Especial de Aquicultura e Pesca indicam existir cerca de 390.761 pescadores artesanais no Brasil, estando $47 \%$ concentrados nos estados do Nordeste. No entanto, as práticas artesanais ainda são, de um modo geral, atividades não regulamentadas no país e sem normas específicas no que diz respeito à proteção, saúde e segurança dos trabalhadores. Grande parte desse trabalho ocorre no setor informal da economia e, por isso, são precárias as informações nos sistemas de vigilância.

A pesca artesanal é um ofício caracterizado principalmente pela mão de obra familiar e envolve saberes adquiridos pela vivência diária com o meio ambiente. Essa tipologia é uma das formas de subsistência de muitas famílias sem aportes sociais, culturais e econômicos e, portanto, é importante pensar em formas de eliminar, diminuir ou prevenir riscos à saúde dos trabalhadores, visando trazer benefícios a qualidade de vida dos mesmos. Para que isso seja possível, devemos essencialmente modelar a atividade de trabalho, o que é possibilitado pela metodologia da Análise Ergonômica do trabalho (AET).

Camilo et al. (2016) afirma que nas práticas artesanais, o conhecimento adquirido se (re)cria ao longo do tempo e confere referências amparadas na tradição, valores e hábitos que são aprendidos. Logo, não é possível realizar mudanças sem uma sensibilização das mesmas. É nesse contexto em que se encontra a antropotecnologia: ciência que estuda a humanidade e a tecnologia. De acordo com estudos de Wisner (2003), a antropotecnologia consiste de um modo geral, na transferência de tecnologia sendo sensível aos fatores técnicos, culturais, sociais, econômicos, geográficos, dentre outras peculiaridades da situação.

Para que o design possa contribuir de forma significativa para otimizar as produções artesanais, deve-se priorizar os requisitos ergonômicos de forma que estes possibilitem maximizar o conforto, bem-estar, a satisfação e a segurança do usuário, trazendo modificações positivas no trabalho, sem, no entanto, descaracterizar a tradição e a cultura dos atores envolvidos. Portanto, a metodologia AET empregada sob esse contexto, possibilitará a discussão e a inserção da ergonomia e do design enquanto fator de melhoria nas produções artesanais, mais especificamente na produção artesanal do molusco sururu.

\section{A produção artesanal do sururu}

Dentre suas riquezas, Alagoas se destaca por uma culinária tipicamente baseada em frutos do mar, em função das lagoas costeiras pertencentes ao estado. É dentro desse contexto em que se encontra o sururu: molusco bivalve fartamente utilizado na culinária alagoana. Segundo a Secretaria de Alagoas (2017), apesar de também situado em outras geografias, encontra-se na Lagoa Mundaú particularidades que dissemina o sururu nos bairros periféricos lacustres, introduzidos em uma paisagem saturada por defasagens sociais e econômicas.

\section{A produção do molusco é artesanal, de natureza extrativista e caracterizada como}

\footnotetext{
1 Designa o animal de corpo mole protegido por um exoesqueleto com forma de uma concha de duas valvas e são mantidas unidas pelos músculos adutores (IPMA, 2017).
} 
uma atividade econômica primária. Seu processo de produção é realizado através de uma cadeia composta por uma rede de atividades na qual homens, mulheres, jovens e até mesmo crianças participam em uma espécie de mão de obra familiar.

\section{Cadeia produtiva do sururu: identificação de demandas}

Através de pesquisas bibliográficas juntamente à pesquisa preliminar de campo, foi possível descrever o ambiente, os process0s, métodos e as condições de trabalho que envolvem o ofício. As fases e subfases que compõem a cadeia podem ser observadas no esquema abaixo.

Figura 1 - Processos da cadeia produtiva do sururu. Fonte: elaborado pela autora, com base na pesquisa realizada (2017).

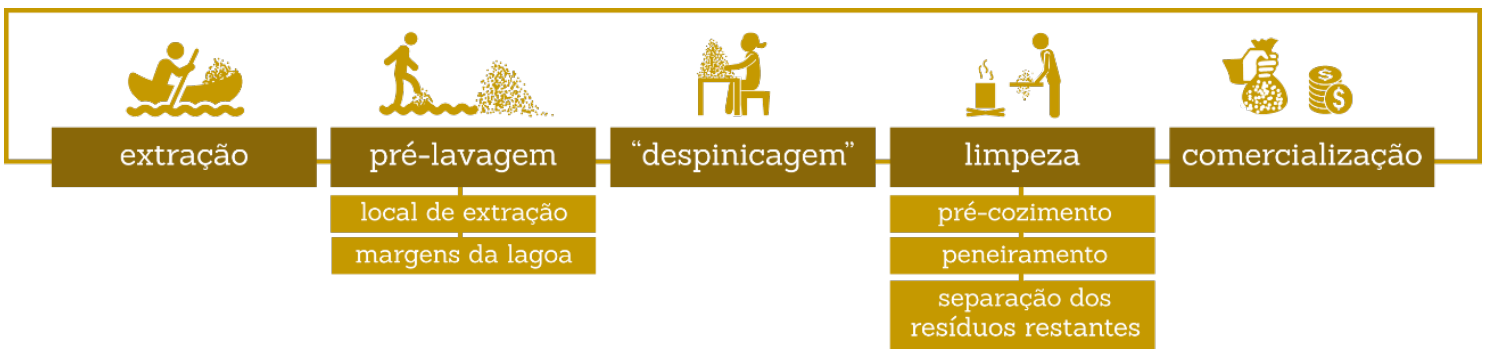

Como resultado dessa cadeia que é iniciada a partir da extração do sururu até a sua comercialização, têm-se uma longa e árdua jornada de trabalho no qual os trabalhadores submetem-se a seguidas condições inadequadas de um ofício realizado em um ambiente insalubre, desprovido de saneamento básico e subsídios governamentais.

\section{Extração}

A fase inicial da cadeia produtiva consiste na extração artesanal do molusco do fundo da lagoa. Em função da exigência de habilidades e de condições físicas, essa etapa é executada predominantemente por homens. Na madrugada, os pescadores dirigem-se de canoa ao local onde habita o molusco e submergem repetidas vezes na lagoa em uma profundidade média de 1,5m retirando da lama grandes quantidades de sururu que são trazidas em recipientes e alocados na canoa, em um trabalho braçal e extremamente desgastante.

Para encher uma canoa de porte médio, cada pescador realiza cerca de 2 mil mergulhos, sendo 20 segundos o tempo médio de cada submersão. Os mergulhos são realizados por meio de apneias (em sua maioria sem equipamentos de proteção). Quando ocorre o uso de algum equipamento, normalmente são óculos aquáticos simples e luvas para protegerem-se da casca pontiaguda do molusco. No entanto, as luvas desgastam-se facilmente e acabam por não impedir os ferimentos e calos.

Figura 2 - Procedimentos realizados na etapa de extração. Fonte: screenshot retirada de documentário disponível online (2012).

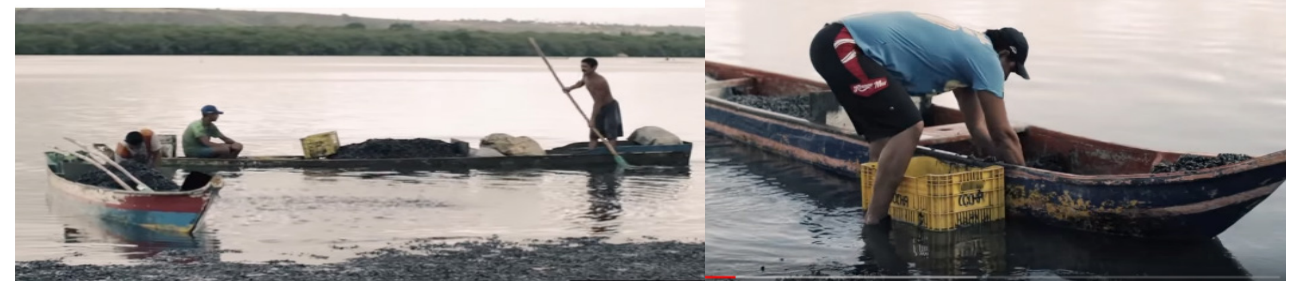


Figura 3 - Pescador com calos na mão em função da atividade. Fonte: acervo da autora (2017).

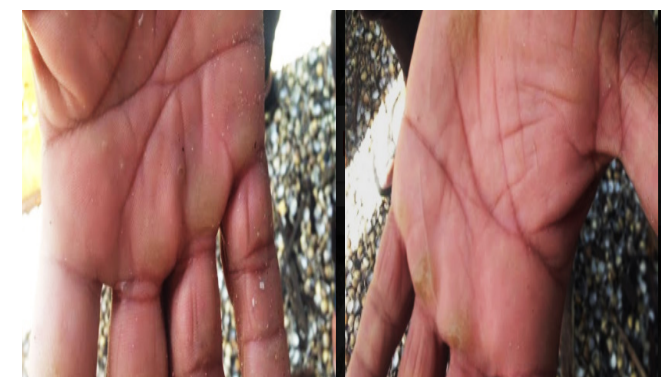

Após encher a canoa pouco a pouco, os pescadores descarregam os moluscos extraídos na margem da lagoa, e voltam ao ponto de extração para dar início à uma nova coleta. Esse ciclo de extração-transporte-descarga é repetido em torno de 3 vezes, podendo durar até $12 \mathrm{~h}$ corridas de trabalho, até então finalizar-se a primeira fase.

\section{Pré-lavagem}

Após a extração do molusco, realiza-se uma pré-lavagem do mesmo. Essa fase geralmente é dividida em duas subfases, na qual a primeira ocorre no local de extração e a segunda ocorre após a descarga do sururu às margens da lagoa. Essa etapa consiste na retirada de grande parte da lama contida no sururu e é executada pelos próprios pescadores no local de extração. Na segunda subfase, ocorre a participação de crianças/ adolescentes no processo, exercendo os mesmos procedimentos dos adultos.

Figura 4 - Pré-lavagem realizada através de um excesso rítmico. Fonte: screenshot retirada de documentário disponível online (2012).

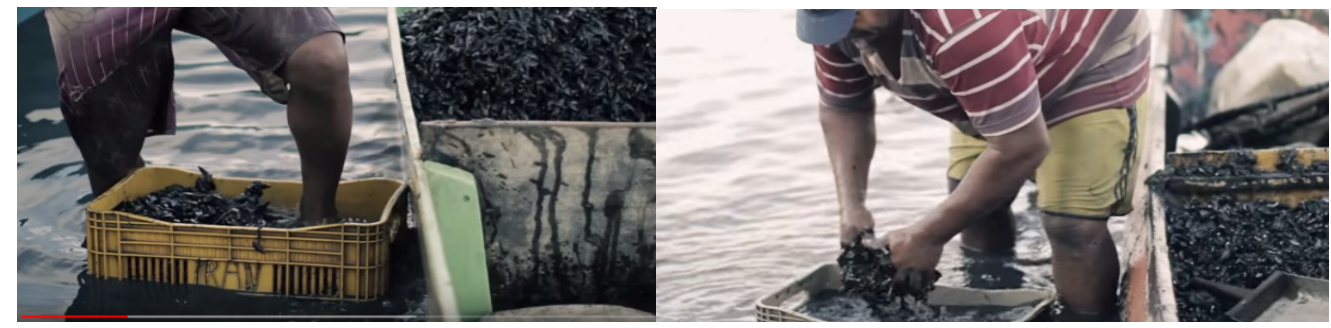

O processo de pré-lavagem é executado com os pés e mãos através de um excesso rítmico centrado nos punhos e pernas (figura 4), gerando grande desgaste muscular, além de calos e ferimentos nas mãos e pés, em função da casca cortante do sururu.

Durante esse processo, alguns trabalhadores utilizam luvas e até mesmo meias, em uma tentativa ineficaz de protegerem-se das lesões. Após a lavagem superficial, os sururus são carregados em baldes, latas, caixotes ou carroças e seguem para a próxima etapa de beneficiamento do molusco, geralmente realizada por algum familiar.

\section{“Despinicagem"}

Consiste na remoção de um tentáculo chamado bisso - parte do molusco que se assemelha a uma corda. A remoção é feita predominantemente pelas mulheres marisqueiras (geralmente esposas dos pescadores) no entanto, as crianças e adolescentes também têm uma significativa participação no processo. 
Figura 5 - Esquerda: posto de trabalho improvisado. Fonte: Gustavo Acioli (2007); Direita: movimentos repetitivos centrados nas mãos. Fonte: screenshot retirada de documentário disponível online (2012).

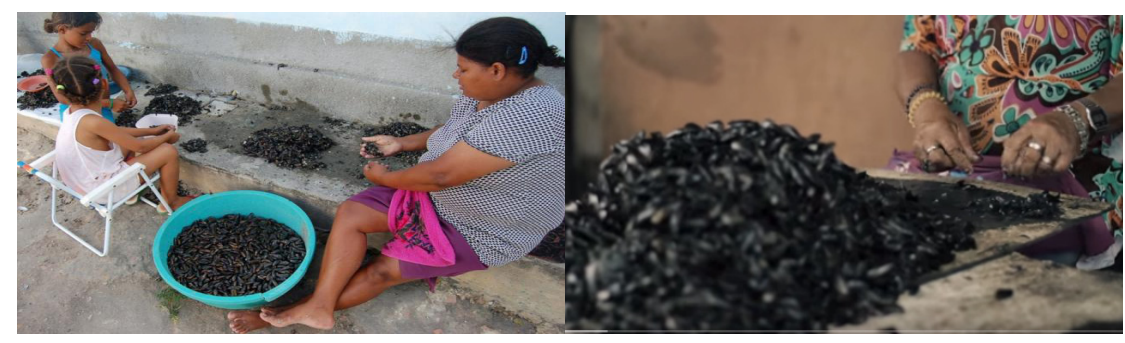

As marisqueiras executam o ofício sentadas no chão, em cadeiras ou bancos rudimentares em um posto de trabalho improvisado. Assim como nos processos anteriores, ocorrem calos e ferimentos nas mãos em função da casca pontiaguda do molusco. Porém, diferentemente das etapas predecessoras, as marisqueiras não utilizam nenhum equipamento para a proteção das mãos, expondo-se ainda mais as lesões. Esse processo perdura períodos que podem chegar em média à 8h diárias realizando movimentos extremamente repetitivos centrados nos punhos e dedos. Finalizada a remoção dos tentáculos, o molusco segue para a fase de limpeza.

\section{Limpeza}

Realizada tanto por adultos quanto por crianças/adolescentes, nessa etapa, iniciamse as operações subsequentes de preparação do molusco para comercialização. Esse processo é dividido em 3 subfases: a primeira consiste no pré-cozimento/fervura do sururu: etapa realizada para que a parte comestível se desprenda facilmente da sua concha através da alta temperatura. Nessa subfase, os trabalhadores fervem o molusco em grandes latas/panelas com fornos improvisados no próprio local, em um processo que dura em média 5 horas.

Figura 6 - Processo de pré-cozimento em fornos improvisados. Fonte: acervo da autora (2017).

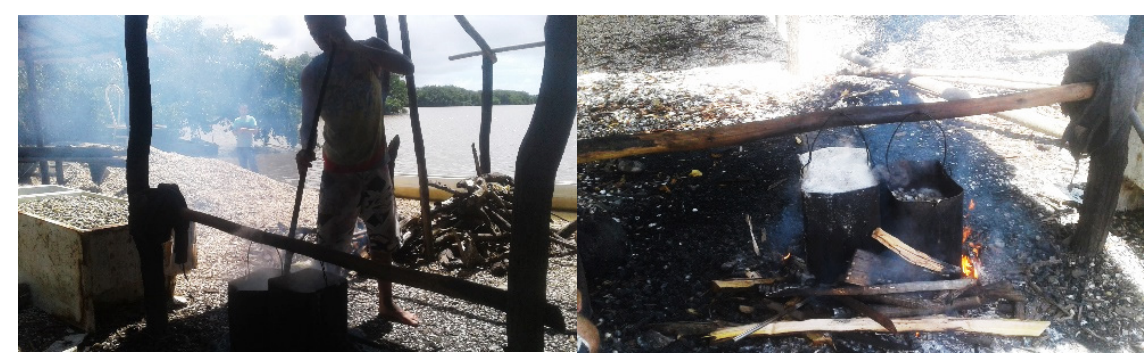

Totalmente desprovidos de equipamentos de proteção, em alguns casos os trabalhadores utilizam panos para protegerem-se de queimaduras ao manipular as latas/ panelas quentes, sujeitando-se à riscos de acidentes, além de sujeitarem-se a exposição direta inalando a fumaça por um longo período. A segunda subfase consiste no peneiramento: etapa em que os trabalhadores movimentam peneiras artesanais repetitivamente, com o objetivo de separar definitivamente a casca do molusco e a parte comestível. 
Figura 7 - Peneiras artesanais utilizadas no processo. Fonte: acervo da autora (2017).

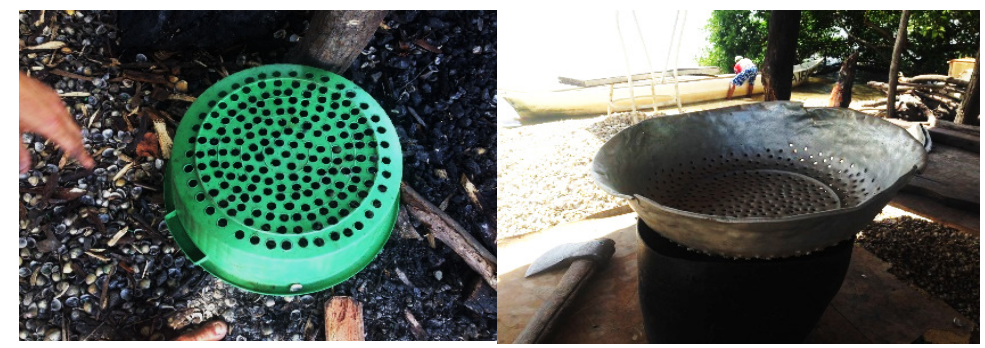

Após o processo, ocorre a separação dos resíduos restantes, no qual os últimos fragmentos de concha são recolhidos, finalizando assim, a terceira subfase de limpeza.

\section{Comercialização}

Após todas as etapas que envolvem o beneficiamento do molusco, o produto é preparado para a comercialização. Para tanto, os trabalhadores realizam a pesagem do sururu e os armazenam em sacos plásticos por quilo. Em muitos casos, o molusco também é armazenado em latas com capacidade média para 16kg e são vendidos para comerciários. A venda e a remuneração ocorrem de forma direta, geralmente em pontos improvisados localizados nas proximidades da comunidade produtora.

Figura 8 - Esquerda: sururu pronto para a comercialização. Fonte: Ailton Cruz (2015); Direita: trabalhadora realizando a pesagem do produto. Fonte: screenshot retirada de documentário disponível online (2012).

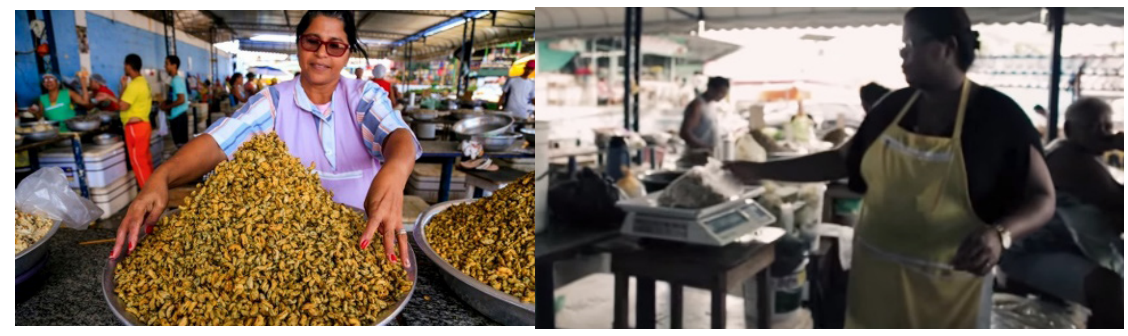

A relação entre a mão-de-obra que envolve a produção e o lucro dos trabalhadores é altamente desproporcional, sendo clara a desvalorização e a exploração presente na cadeia produtiva do sururu. O fato de ser um produto perecível no qual não há condições adequadas de conservação e armazenamento, faz com que o mesmo circule com rapidez e os trabalhadores necessitam vendê-lo por preços abaixo dos valores de mercado. Pena et al (2011), pondera que por estes fatores, a miséria social impõe ritmo intenso de trabalho para gerar mais produtos à venda. Assim, para conseguir o mínimo de renda, todos os integrantes da família necessitam operar na cadeia, entretanto, a renda mensal obtida é muito inferior a 1 salário mínimo, fazendo com que estas populações possuam condições econômicas precárias.

\section{RESULTADOS E DISCUSSÕES}

Considerando o ambiente, os processos, métodos e ferramentas que envolvem as fases e subfases da cadeia produtiva do sururu, fica clara a ausência de um sistema ergonomicamente adequado, no qual estão presentes riscos físicos, químicos e biológicos. Totalmente desprovidos de produtos e equipamentos apropriados para a atividade, os trabalhadores submetem-se diariamente a condições inadequadas em todas as etapas da produção.

As inadequações identificadas abarcam problemas relacionados à postura, inalação de fumaça, ferimentos, sobrecarga física, excesso de movimentos repetitivos e apneias 
contínuas, assim como também a exposição e o contato com o ambiente insalubre. Esses condicionantes tornam os envolvidos propensos a adquirir doenças ocupacionais conforme a relação abaixo.

Figura 9 - Relação entre os problemas e suas respectivas doenças ocupacionais. Fonte: elaborado pela autora, com base na pesquisa realizada (2017).

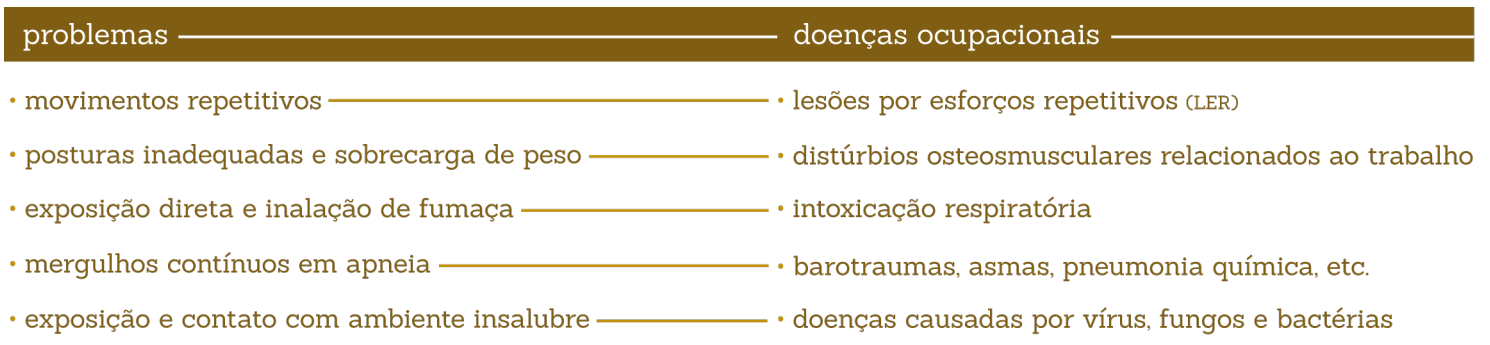

De acordo com Pena et al. (2011), neste processo de trabalho artesanal, as cadências extenuantes resultam da miséria, dadas às condições em que os trabalhadores se submetem ao trabalho para evitar a fome e a marginalização da sua família. Por consequência, acabam por economizar na compra de equipamentos de proteção, negligenciando o cuidado contra os riscos, assim como introduzem o trabalho infantil, permanecem no trabalho com dores locais e prolongam a busca de assistência médica.

Desse modo, através do estudo com foco na análise ergonômica, percebe-se a possibilidade de inserção do design através do desenvolvimento de um produto adequado, de forma que este possa vir a favorecer a produção do ofício, objetivando solucionar demandas que podem influenciar diretamente a qualidade de vida e a produtividade dos trabalhadores. Para tanto, com base nas fundamentações teóricas supracitadas anteriormente, deve-se essencialmente modelar a situação de trabalho sendo sensível aos condicionantes físicos, ambientais, sociais, econômicos e culturais que abrange o ofício e a comunidade envolvida.

\section{REFERÊNCIAS}

ABERGO - Associação Brasileira de Ergonomia. O que é Ergonomia?. Disponível em: < http://www.abergo.org.br/internas.php?pg=o_que_e_ergonomia>. Acesso em: 13 abr. 2017.

BRASIL. Secretaria Especial de Aquicultura e Pesca. Disponível em: <http://www. presidencia.gov.br>. Acesso em 20 set. 2017.

CAMILO, V. M. A. et al. Processamento artesanal de sururu (Mytella Guyanensis) pelas marisqueiras da RESEX Baía do Iguape: avaliação da qualidade antes e após intervenção educativa. Vigilância Sanitária em Debate: Sociedade, Ciência \& Tecnologia, v. 4, n. 4, p. 3442, 2016.

IPMA. Morfologia, biologia e ecologia dos moluscos bivalves. Disponível em: <https:// www.ipma.pt/pt/enciclopedia/pescas/>. Acesso em: 12 abr. 2017.

PAZMINO, Ana V. Uma reflexão sobre design social, eco design e design sustentável. Simpósio Brasileiro de Design Sustentável, v. 1, 2007.

PENA, P. G. L.; FREITAS, M. C. S.; DE CARDIM, A. Trabalho artesanal, cadências infernais e lesões por esforços repetitivos: estudo de caso em uma comunidade de mariscadeiras na Ilha de Maré, Bahia. Ciência \& Saúde Coletiva, v. 16, n. 8, p. 3383-3392, 2011.

PROJETO DE DIAGNÓSTICO DA CADEIA PRODUTIVA DE SURURU NA LAGOA MUNDAÚ, MACEIÓ-AL. Produção do Instituto Brasileiro De Desenvolvimento E Sustentabilidade 
(IABS), 2012. Duração: 7:47 min. Disponível em: shttps://www.youtube.com/ watch?v=_05n10XB_aA>. Acesso em: 15 abr. 2017.

SURURU: A CADEIA PRODUTIVA DA MISÉRIA. Produção de Gesia Malheiros, 2017. Duração: 33:15 min. Disponível em: 〈https://www.youtube.com/watch?v=dklUtPw2mEA . Acesso em: 20 abr. 2017.

VIDAL, M. C. R. Guia para Análise Ergonômica do Trabalho (AET) na empresa: uma metodologia realista, ordenada e sistemática. Rio de Janeiro: Virtual Científica, 2008. ; Conversa-ação - A interação orientada na ação ergonômica. In: Linguagem e trabalho. Ed. Lucerna, 1998.

WISNER, A. A antropotecnologia. Estudos avançados, v. 6, n. 16, p. 29-34, 1992.

Sobre os autores:

Steffane Luiza Costa Neves (graduanda), UFAL <steffaneluiza旬hotmail.com>

Juliana Donato de Almeida Cantalice (doutoranda), UFAL <juliana.donato@fau.ufal.br> 